\title{
Structural and electrical-physical properties of the ohmic contacts based on palladium to $n^{+}-n-n^{++}-n^{+++}-$InP
}

\author{
A.E. Belyaev ${ }^{1}$, N.A. Boltovets ${ }^{2}$, A.B. Bobyl ${ }^{3}$, V.P. Kladko ${ }^{1}$, R.V. Konakova ${ }^{1}$, \\ Ya.Ya. Kudryk', M.U. Nasyrov ${ }^{1}$, A.V. Sachenko', V.S. Slipokurov ${ }^{1}$, \\ A.S. Slepova ${ }^{2}$, N.V. Safryuk ${ }^{1}$, A.I. Gudymenko ${ }^{1}$, V.V. Shynkarenko' \\ ${ }^{1}$ V. Lashkaryov Institute of Semiconductor Physics, National Academy of Sciences of Ukraine \\ 41, prospect Nauky,03680 Kyiv,Ukraine, e-mail: konakova@isp.kiev.ua \\ ${ }^{2}$ State Enterprise Research Institute "Orion”, 03057 Kyiv, Ukraine \\ ${ }^{3}$ A.F. Ioffe Physical-Technical Institute, Russian Academy of Sciences, \\ 197101, St. Petersburg, Russian Federation
}

\begin{abstract}
Presented in this paper are experimental data on structural properties of contact metallization and temperature dependence of the specific contact resistance for ohmic contacts $\mathrm{Au}-\mathrm{Ti}-\mathrm{Pd}-n^{+}-\mathrm{InP}$ and $\mathrm{Au}-\mathrm{Ti}-\mathrm{Ge}-\mathrm{Pd}-n^{+}-\mathrm{InP}$ prepared using the method of successive thermal evaporation of metals in oil-free vacuum in one process cycle onto the $n^{+}-n-n^{++}-n^{+++}-$InP epitaxial structure heated to $300{ }^{\circ} \mathrm{C}$. It has been theoretically and experimentally shown that within the temperature range $250 \ldots 380 \mathrm{~K}$ the current transport mechanism in the ohmic contacts $\mathrm{Au}-\mathrm{Ti}-\mathrm{Pd}-n^{+}-\mathrm{InP}$ is thermal-field one, and in the ohmic contacts $\mathrm{Au}-\mathrm{Ti}-\mathrm{Ge}-\mathrm{Pd}-n^{+}-\mathrm{InP}$ it is caused by conductivity along metal shunts linked with dislocations. According to the X-ray diffraction data, the density of these dislocations in the near-contact InP area is $\sim 10^{9} \mathrm{~cm}^{-2}$.
\end{abstract}

Keywords: ohmic contacts, specific contact resistance, InP, current transport mechanism.

Manuscript received 09.06.15; revised version received 10.09.15; accepted for publication 28.10.15; published online 03.12.15.

\section{Introduction}

Indium phosphide is one of the main semiconductor materials currently used for manufacturing Gunn diodes and field-effect transistors with high mobility - highelectron mobility transistor (HEMT) of millimeter and submillimeter wavelengths [1-4]. These devices are characterized with very small dimensions. Therefore, it is natural to demand high structural homogeneity to forming contact layers and the interface metal-InP. This requirement applies equally to both rectifying (barrier) and nonrectifying (ohmic) contacts. For ohmic contacts to the indium phosphide microwave devices, goldgermanium eutectic is most often used.
For all the merits of such contact (it is known since the first experiments on GaAs Gunn diode [5]), the presence of interfacial interactions, which are accompanied by formation of a number of new phases that originate in the process of formation of ohmic contacts and possible overloads in the operation of devices in electronic sets, causes significant heterogeneity of the interface 'forming contact layer InP'. In this case, the phases originating at relatively low temperatures do not break down at higher ones, too [6]. It leads to a non-uniform distribution of the current density over the contact area. In addition, the heterogeneity in the height of the barrier arises [7]. I.e., the layered structure not only of contact metallization, 
but the area of the interface 'forming contact layer - InP' is significantly broken. Therefore, still there is a necessity to search for optimizing the parameters of the ohmic contacts to InP and methods of their manufacturing [8-10].

For example, formation of the contact metallization to InP with the first deposited metal layer, contributing to improvement of adhesion. This layer is called as adhesive one having oxidation resistance and relatively low temperature of reaction with InP, which should provide adhesion. Annealing of the contact metallization with the adhesive layer within the temperature range 300 to $450{ }^{\circ} \mathrm{C}$ results in formation of an ohmic contact. Thus, when preparing the ohmic contact $\mathrm{Pd}-n$-InP $\left(n \approx 10^{17} \mathrm{~cm}^{-3}\right)$ using electron-beam evaporation, followed by annealing within the temperature range $300 \ldots 375^{\circ} \mathrm{C}$, a minimum specific contact resistivity of $\sim 4.2 \cdot 10^{-6} \mathrm{Ohm} \cdot \mathrm{cm}^{2}$ was obtained [11].

When creating the ohmic contact $\mathrm{Au}-\mathrm{Ge}-\mathrm{Pd}-n$-InP ( $n \approx 10^{17} \mathrm{~cm}^{-3}$ ) by using the same technological process, but with annealing within the temperature range $350 \ldots 450{ }^{\circ} \mathrm{C}$, the minimum value $\rho_{c}$ was close to $2.5 \cdot 10^{-6} \mathrm{Ohm} \cdot \mathrm{cm}^{2}$ [11]. At the same time, up to date for these contacts a number of important physical and technological parameters have not been studied, including temperature dependences of $\rho_{c}$, influence of structural defects that originate during annealing and cooling the samples in the area of the interface 'forming contact layer - InP' due to relaxation of internal mechanical strains on the value $\rho_{c}$ and dependence $\rho_{c}(T)$. We also note a particular interest of developers of technology for devices based on $\mathrm{A}^{3} \mathrm{~B}^{5}$ compounds to the reduction of the number of heat treatments, which, on the one hand, reduces the cost of production of devices and, on the other hand, improves the quality of the active elements. Currently, non-annealed ohmic contacts are used in the technological process of creation of HEMT based on the compounds $\mathrm{A}_{3} \mathrm{~N}$ [12].

Below, the research of ohmic contacts based on palladium to the epitaxial structure $n^{+}-n-n^{++}-n^{+++}-\mathrm{InP}$ is presented. The ohmic contacts $\mathrm{Au}-\mathrm{Ti}-\mathrm{Pd}-n^{+}-\mathrm{InP}$ and $\mathrm{Au}-\mathrm{Ti}-\mathrm{Ge}-\mathrm{Pd}-n^{+}-\mathrm{InP}$ were created to the upper epitaxial $n^{+}$-layer InP.

\section{Samples and research methods}

There were investigated two types of the samples: the test structures for measuring specific contact resistivity $\rho_{c}$ within the temperature range $250 \ldots 380 \mathrm{~K}$ with the use of transmission line method (TLM) and the test structures with continuous metallization for measuring the profile of distribution of the components as well as phase composition of the contact metallization by the methods of Auger electron spectroscopy and X-ray diffractometry, respectively. The elemental composition was measured using Auger spectrometer LAS-2000, the phase composition and deformation effects - setup ARL X'Tra (Thermo scientific) with $\mathrm{CuK} \alpha$ radiation and database ICDD, PDF-2 Release 2012.
Ohmic contacts were formed using the method of successive thermal deposition of metals in oil-free vacuum in a single processing cycle onto heated to $300{ }^{\circ} \mathrm{C}$ substrate that is epitaxial structure $n^{+}-n-n^{++}-n^{+++}-\mathrm{InP}$ obtained using gas-phase epitaxy. The structure parameters are the concentration of the donor impurity (Si) in the layers: $n^{+}-10^{18} \mathrm{~cm}^{-3}, n-8 \cdot 10^{15} \mathrm{~cm}^{-3}, n^{++}$ $5 \cdot 10^{17} \mathrm{~cm}^{-3}, n^{+++}-2 \cdot 10^{18} \mathrm{~cm}^{-3}$, the thicknesses of the layers: $0.2,15,3$, and $300 \mu \mathrm{m}$, respectively. The ohmic contacts $\mathrm{Au}(100 \mathrm{~nm})-\mathrm{Ti}(40 \mathrm{~nm})-\mathrm{Pd}(30 \mathrm{~nm})-n^{+}-\mathrm{InP}$ and $\mathrm{Au}(200 \mathrm{~nm})-\mathrm{Ti}(40 \mathrm{~nm})-\mathrm{Ge}(60 \mathrm{~nm})-\mathrm{Pd}(30 \mathrm{~nm})-$ $n^{+}$-InP were formed during the deposition process and not subjected to the additional annealing.

\section{Experimental results and discussion}

Figs 1 and 2 shows the profiles of distribution of the components in the contact metallization $\mathrm{Au}-\mathrm{Ti}-\mathrm{Pd}-$ $n^{+}$-InP and $\mathrm{Au}-\mathrm{Ti}-\mathrm{Ge}-\mathrm{Pd}-n^{+}-\mathrm{InP}$ formed on the heated to $300{ }^{\circ} \mathrm{C}$ substrates. As seen from these figures, both types of contacts have a layered structure. In both cases, the increased content of oxygen and carbon in the titanium film is observed. For the sample $\mathrm{Au}-\mathrm{Ti}-\mathrm{Ge}-$ $\mathrm{Pd}-n^{+}$-InP (Fig. 2), typical is the mass transport of $\mathrm{Ge}$ into the thin near-contact area of InP, which causes the increase in the concentration of the donor impurity $(\mathrm{Ge}$ is the donor in InP [13]) in this area. The peculiarity of the near-contact area of InP in both samples is its multicomponent character, as can be seen from Figs 1 and 2.

The XRD analysis of the test structures with both types of metallization has shown the presence of reflections from the polycrystalline $\mathrm{Au}$ and $\mathrm{Ti}$ films (Figs 3 and 4) and absence of corresponding reflections from $\mathrm{Ge}$ and $\mathrm{Pd}$ or their compounds with InP. As Pd and $\mathrm{Ge}$ are observed in the corresponding profiles of the contact metallization to $n^{+}$-InP (Figs 1 and 2), it can be assumed that during deposition of metal on a heated to $300{ }^{\circ} \mathrm{C}$ substrate, the products of the phase formation are created in the amorphous phase. This assumption does not contradict the available data in the literature about the ohmic contacts to InP based on palladium [11, 14].

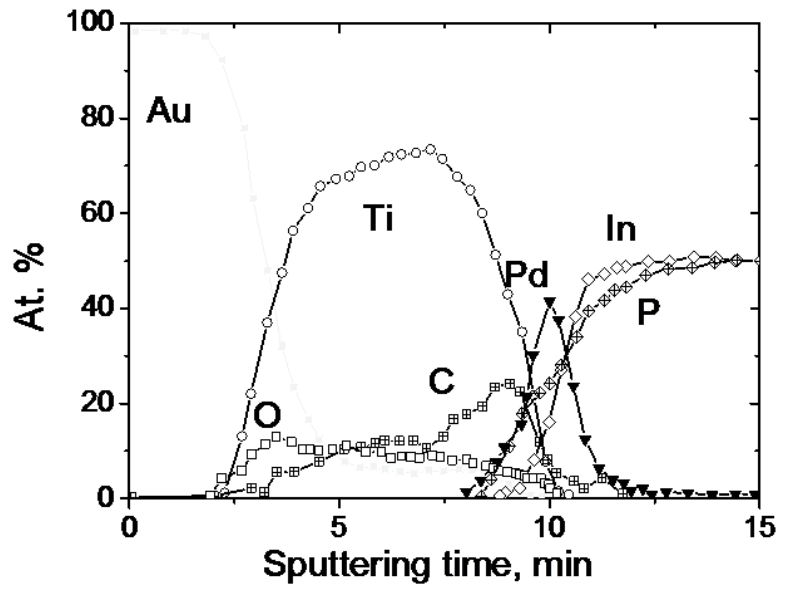

Fig. 1. Profiles of component distribution in the contact metallization $\mathrm{Au}-\mathrm{Ti}-\mathrm{Pd}-n^{+}-\mathrm{InP}$. 


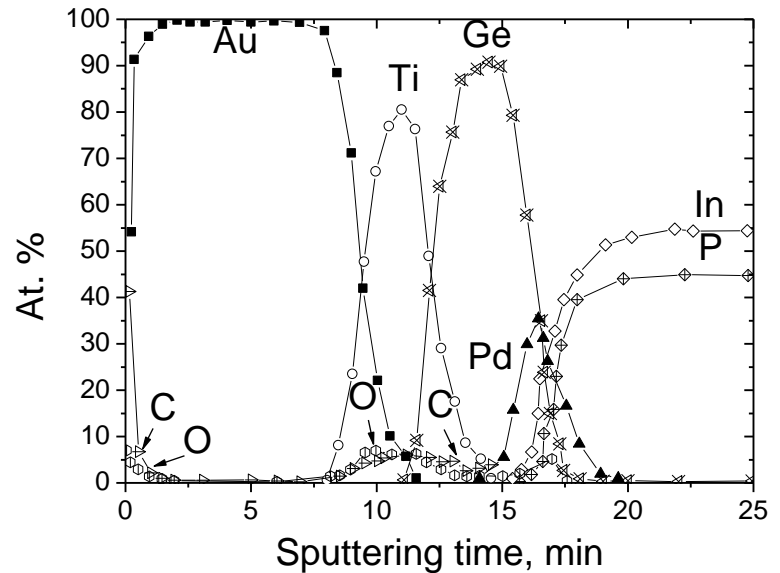

Fig. 2. Profiles of component distribution in the contact metallization $\mathrm{Au}-\mathrm{Ti}-\mathrm{Ge}-\mathrm{Pd}-n^{+}-\mathrm{InP}$.

The analysis of diffraction spectra indicates the difference in the elastic-strain state of two contact systems. In particular, for the system $\mathrm{Au}-\mathrm{Ti}-\mathrm{Pd}-n^{+}-\mathrm{InP}$ (Fig. 3), the values of deformations in the contact metallization is about 0.014 , while for the system $\mathrm{Au}-$ $\mathrm{Ti}-\mathrm{Ge}-\mathrm{Pd}-n^{+}-\mathrm{InP}$ (Fig. 4) this value is lower; i.e., the contact $\mathrm{Au}-\mathrm{Ti}-\mathrm{Ge}-\mathrm{Pd}-n^{+}-\mathrm{InP}$ is more relaxed $[15,16]$. The analysis of the deformation state of the contact systems shows that the main mechanism of relaxation of strains in the system $\mathrm{Au}-\mathrm{Ti}-\mathrm{Ge}-\mathrm{Pd}-n^{+}-\mathrm{InP}$ is generation of dislocations in the near-contact area of InP with the density of the order of $10^{9} \mathrm{~cm}^{-2}$. It is these defects of this type that are the main cause of the structural heterogeneity in the near-contact area.

The voltage-current characteristics of the contacts $\mathrm{Au}-\mathrm{Ti}-\mathrm{Pd}-n^{+}-\mathrm{InP}$ and $\mathrm{Au}-\mathrm{Ti}-\mathrm{Ge}-\mathrm{Pd}-n^{+}-\mathrm{InP}$ within the temperature range $250 \ldots 380 \mathrm{~K}$ were linear. The temperature dependences $\rho_{c}$ to these contacts measured within the temperature range $250 \ldots 380 \mathrm{~K}$ are shown in Fig. 5. The analysis of the dependences $\rho_{c}(T)$ showed that for the ohmic contacts $\mathrm{Au}-\mathrm{Ti}-\mathrm{Pd}-n^{+}-\mathrm{InP}$ (empty points in the curve 1, Fig. 5) thermal-field current transport mechanism is characteristic, for $\mathrm{Au}-\mathrm{Ti}-\mathrm{Ge}-$ $\mathrm{Pd}-n^{+}$-InP (filled points in the curve 2, Fig. 5) - the current transport mechanism through metal shunts. In what follows, they will be considered in more detail.

Let plot a relationship $\rho_{c}(T)$ for ohmic contact $\mathrm{Au}-$ $\mathrm{Ti}-\mathrm{Pd}-n^{+}-\mathrm{InP}$ in accordance with the modified formula for the thermal-field current transport mechanism [17]:

$$
\begin{aligned}
& \rho_{T F}=\frac{k \sqrt{E_{00}} \cosh \left(\frac{E_{00}}{k T}\right) \operatorname{coth}\left(\frac{E_{00}}{k T}\right)}{A\left(\frac{m^{*}}{m_{0}}\right) T q \sqrt{\pi\left(\varphi_{c}-E_{\mathrm{F}}\right)}} \times \\
& \times \exp \left[\frac{\varphi_{c}-E_{\mathrm{F}}}{E_{00} \operatorname{coth}\left(\frac{E_{00}}{k T}\right)}+\frac{E_{\mathrm{F}}}{k T}\right],
\end{aligned}
$$

where $\rho_{\mathrm{TF}}$ is the specific contact resistivity in the case of the thermal-field current transport mechanism, $k-$ Boltzmann constant, $T$ - temperature, $q$ - elementary charge, $m^{*}$ - effective mass of electron, $m_{0}$ - free electron mass, $\varphi_{c}$ - potential energy of electron, i.e., the barrier height at the interface metal-semiconductor, $E_{00}=0.054\left(\left(m_{0} / m^{*}\right)\left(N_{d} / 10^{20}\right)\left(11.7 / \varepsilon_{s}\right)\right)^{0.5}$ characteristic energy of tunneling, $\varepsilon_{s}-$ dielectric constant of semiconductor, $A$ - the Richardson constant, $E_{\mathrm{F}}-$ the Fermi energy, $N_{d}$ - donor concentration. Indeed, as can be seen from a comparison of the experimental and theoretical dependences $\rho_{c}(T)$ (Fig. 5, curve 1: dots experiment, line - calculation), they are in good agreement with each other. The coincidence is achieved in the case where the barrier height is $0.28 \mathrm{eV}$.

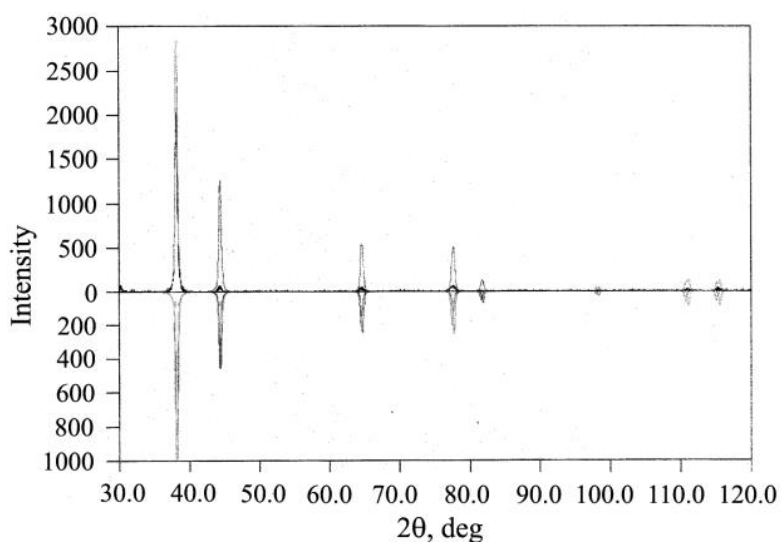

Fig. 3. Experimental diffraction pattern of the contact metallization $\mathrm{Au}-\mathrm{Ti}-\mathrm{Pd}-n^{+}-\mathrm{InP}$ (upper curve) and calculated diffraction patterns for $\mathrm{Au}$ and $\mathrm{Ti}$ (lower curves).

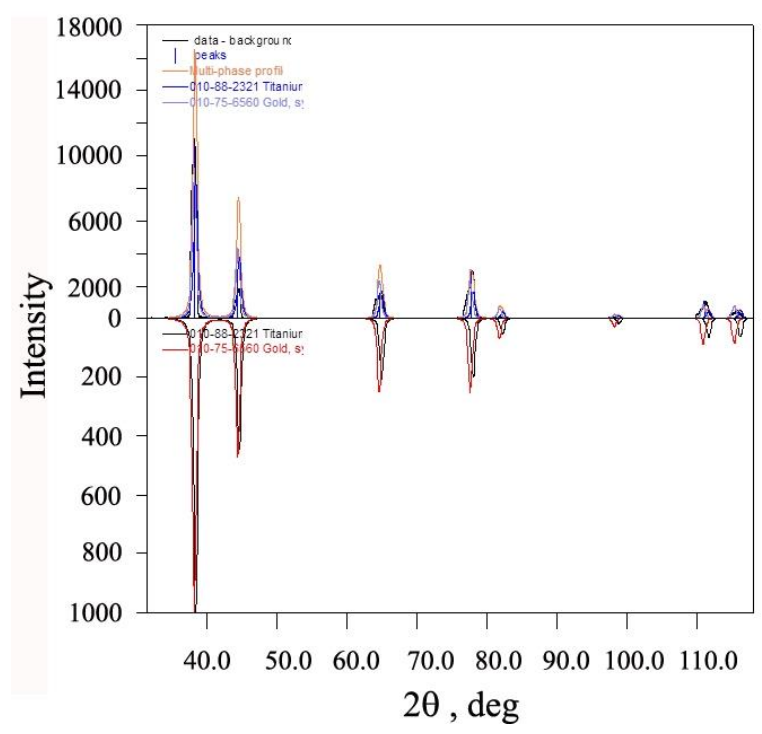

Fig. 4. Experimental diffraction pattern of the contact metallization $\mathrm{Au}-\mathrm{Ti}-\mathrm{Ge}-\mathrm{Pd}-n^{+}-\mathrm{InP}$ (upper curves) and calculated diffraction patterns for $\mathrm{Au}$ and $\mathrm{Ti}$ (lower curves). 


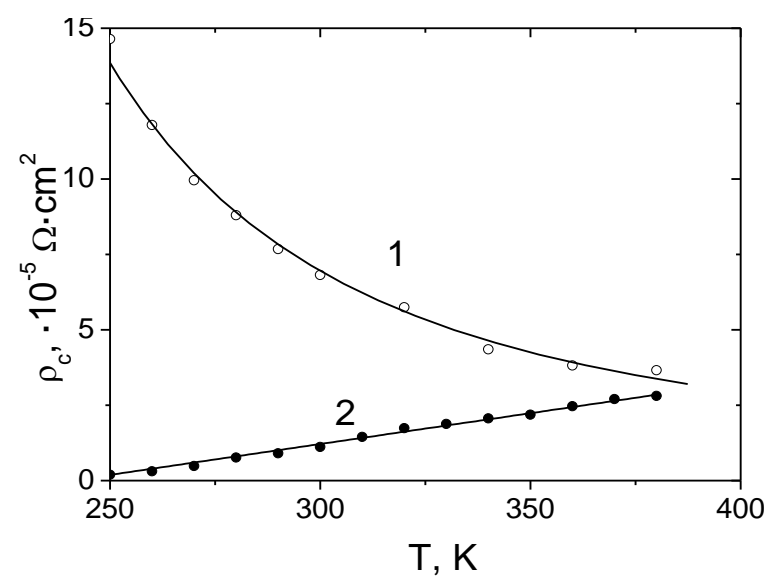

Fig. 5. Temperature dependence of the specific contact resistance $\left(1-\mathrm{Au}-\mathrm{Ti}-\mathrm{Pd}-n^{+}-\mathrm{InP}, 2-\mathrm{Au}-\mathrm{Ge}-\mathrm{Ti}-\mathrm{Pd}-n^{+}-\mathrm{InP}\right.$, dots - experiment, lines - calculation).

Since the literature data on the dependence $\rho_{c}(T)$ for ohmic contacts based on Pd are absent, let's compare the $\rho_{c}$ values measured at room temperature [14] with those obtained in our work. Thus, the ohmic characteristics for contact Pd-InP were observed after annealing at $T=300{ }^{\circ} \mathrm{C}$ and were caused by the presence of the phase PdIn. For such a contact, the $\rho_{c}$ value at room temperature was about $6 \cdot 10^{-5} \mathrm{Ohm} \cdot \mathrm{cm}^{2}[14] . \rho_{c}$ of the same order was obtained in our work after deposition of metals $(\mathrm{Pd}, \mathrm{Au}$ and $\mathrm{Ti}$ ) onto the substrate heated to $300{ }^{\circ} \mathrm{C}$ (Fig. 5, curve 1 ).

Our data on $\rho_{c}(T)$ as well as on the phase and chemical composition of the contact metallization of $\mathrm{Au}-\mathrm{Ti}-\mathrm{Pd}-n^{+}-\mathrm{InP}$ indicate relatively uniform interface 'forming contact layer - InP' created directly during deposition of the contact metallization on the InP substrate heated to $300{ }^{\circ} \mathrm{C}$ without subsequent heat treatment.

The analysis of the ohmic contacts, in which the composition together with the adhesion layer $\mathrm{Pd}$ includes $\mathrm{Ge}$, has shown that at room temperature for different samples and annealing conditions, $\rho_{c}$ varies within the range $10^{-5} \ldots 2.5 \cdot 10^{-6} \mathrm{Ohm} \cdot \mathrm{cm}^{2}$ according to [14]. In our work (Fig. 5, curve 2), during deposition of metals ( $\mathrm{Pd}, \mathrm{Ge}, \mathrm{Ti}$, and $\mathrm{Au})$ on the heated to $300{ }^{\circ} \mathrm{C}$ substrate, at room temperature $\rho_{c}$ is close to $1.2 \cdot 10^{-5} \mathrm{Ohm} \cdot \mathrm{cm}^{2}$. I.e., as in the previous case (contact $\left.\mathrm{Au}-\mathrm{Ti}-\mathrm{Pd}-n^{+}-\mathrm{InP}\right)$, the $\rho_{c}$ value is of the same order as those of the samples, in which the ohmic contact has formed after annealing.

In the theoretical simulation of the dependence $\rho_{c}(T)$ for the ohmic contact $\mathrm{Au}-\mathrm{Ti}-\mathrm{Ge}-\mathrm{Pd}-n^{+}-\mathrm{InP}$, we take into account that in this case the subcontact layer $n^{+}$-InP is strongly degenerated due to subdoping with germanium. As seen from Fig. 5 (curve 2), at $T>250 \mathrm{~K}$ $\rho_{c}(T)$ is linearly dependent on the temperature. In accordance with [18], we assume that the current transport occurs through the metal shunts linked with dislocations. To calculate $\rho_{c}(T)$, we use the expressions [18] valid for the case of degenerated semiconductor.
Following [18], we write an expression for the specific contact resistivity $\rho_{t w}$ that is determined by the supply of electrons from semiconductor into the ends of shunts for the contact of unit area

$$
\rho_{t w}=\frac{k}{q \pi N_{D 1} L_{\mathrm{D}}^{2} A\left(m^{*} / m_{0}\right) T} \frac{1}{\ln \left[1+\exp \left(z+y_{c 0}\right)\right]},
$$

where $N_{D 1}$ is the density of conductive dislocations, $L_{\mathrm{D}}-$ Debye screening length, $y_{c 0}-$ dimensionless (normalized to $k T$ ) contact potential. In the considered case, the dimensionless Fermi energy $z$ (normalized to $k T$ ) is determined from the equation of volume neutrality:

$N_{d}=\frac{2}{\sqrt{\pi}} N_{c 0}\left(\frac{T}{300}\right)^{3 / 2} \int_{0}^{\infty} \frac{x}{1+\exp (x-z)} d x$,

where $N_{c 0}$ is the effective density of states in the conduction band.

It should be noted that the stronger degenerated semiconductor, the weaker the value $\rho_{t w}$ depends on the temperature, and with threshold levels of degeneration when $z+y_{c 0} \gg 1$, the dependence $\rho_{t w}$ is absent. Since the resistivity of all the metal shunts $\rho_{s h}$ is connected in series with the resistivity $\rho_{t w}$ in the case of degenerated semiconductor, the relation for the total resistivity of the ohmic contact in semiconductor with a high dislocation density is written as

$\rho_{c}=\rho_{t w}+\rho_{s h}$.

$$
\text { Here, } \rho_{s h}=R_{s h}(T) / N_{D 1} \text { and } R_{s h}(T)=\frac{\rho_{0}(T) d_{D}}{\pi r^{2}}
$$

is the temperature dependence of the resistance of metal shunt, where $\rho_{0}$ is the specific resistivity, $d_{D}-$ dislocation length, $r$ - shunt radius (in the calculation, all the shunts are considered to be identical). It is assumed that the current flowing between dislocations can be neglected in comparison with the current flowing through these dislocations. It is provided by the large value of the barrier formed between dislocations [18].

The temperature dependence $\rho_{s h}(T)$ with account of the temperature dependence of the resistivity of forming contact metal at $T>250 \mathrm{~K}$ is linear, since $T \geq T_{\mathrm{D}}$, where $T_{\mathrm{D}}$ is the Debye temperature, i.e., the metal resistance increases linearly with the temperature: $\rho_{0}(T)=\rho_{00}(1+\alpha(T-250))$, where $\alpha$ is the temperature coefficient of resistance.

The theoretical curve for the dependence $\rho_{c}(T)$ was calculated using the formula (4). As can be seen from Fig. 5 (curve 2, line is calculation, points - experiment), there is a good agreement between the calculated dependence of the specific contact resistivity $\rho_{c}$ with the experimental data. It is achieved by using the following parameters: $N_{D 1} \approx 10^{9} \mathrm{~cm}^{-2}, r \approx 6 \cdot 10^{-8} \mathrm{~cm}, d_{D} \sim 0.1 \mu \mathrm{m}$, $\alpha \approx 3 \cdot 10^{-2} \mathrm{~K}^{-1}$. Estimation of the dislocation density obtained from the X-ray diffraction data almost coincides with the $N_{D 1}$ value calculated using the formula (4). 
Attention is drawn to the fact that in this case the $\alpha$ value is much higher than the temperature coefficient of resistance growth for pure metals. It may be caused by the fact that in this case forming contact layer is a multicomponent alloy.

It has been shown that the ohmic contacts $\mathrm{Au}-\mathrm{Ti}-$ $\mathrm{Pd}-n^{+}$-InP, formed by successive thermal deposition of metals in oil-free vacuum onto the $n^{+}-n-n^{++}-n^{+++}-\mathrm{InP}$ substrate heated to $300{ }^{\circ} \mathrm{C}$ have linear $\mathrm{CVC}$ within the temperature range $250 \ldots 380 \mathrm{~K}$. The temperature dependence $\rho_{c}$ in this case is described by the thermal field emission mechanism. This fact distinguishes the contact $\mathrm{Au}-\mathrm{Ti}-\mathrm{Pd}-n^{+}-n-n^{++}-n^{+++}-\mathrm{InP}$ from the ohmic contact $\mathrm{Au}-\mathrm{Ti}-\mathrm{Ge}-\mathrm{Pd}-n^{+}-n-n^{++}-n^{+++}-\mathrm{InP}$, in which its advantage, associated with subdoping of the near-contact area of InP with germanium, offset by the structural heterogeneity of contact, causing linear increase in $\rho_{c}$ with increasing the temperature.

\section{References}

1. H. Eisele, R. Kamua, Submillimeter-Wave InP Gunn Devices // IEEE Trans. MTT, 52(10), p. 2371-2378 (2004).

2. H. Eisele, $480 \mathrm{GHz}$ oscillator with an InP Gunn device // Electron. Lett. 46(6), p. 422-423 (2010).

3. V. Papageorgiou, A. Khalid, C. Li, D.R.S. Cumming, Cofabrication of planar Gunn diode and HEMT on InP substrate // IEEE Trans. Electron. Dev. 61(8), p. 2279-2784 (2014).

4. M.I. Maricar, A. Khalid, G. Dunn, D. Cumming, C.H. Oxley, Experimentally estimated dead space for GaAs and InP based planar Gunn diodes // Semicond. Sci. Technol. 30, p. 012001-012005 (2015).

5. N. Braslau, J.B. Gunn, J.L. Staples, Metal-semiconductor contact for GaAs bulk effect devices // Solid-State Electron. 10(5), p. 381-383 (1967).

6. P. Auray, A. Guivarc'h, H.L'Haridon, J.P. Mercier, Formation, microstructure et resistances des contacts $\mathrm{Au}-\mathrm{Ge} / \mathrm{n}-\mathrm{GaAs}, \mathrm{Au}-\mathrm{Ge} / \mathrm{n}-\mathrm{InP}, \mathrm{Au}-\mathrm{Zn} / \mathrm{p}-$ InP et Au-Be/p-InP // Thin Solid Films, 127(1), p. 39-68 (1985).
7. R.T. Tung, The physics and chemistry of the Schottky barrier height // J. Appl. Phys. Rev. 1, p. 011304-1-01130454 (2014).

8. T. Clausen, O. Leistiko, Metallurgical optimization for ohmic contacts to InP using conventional metallization schemes // Microelectron. Eng. 18(4), p. 305-325 (1992).

9. M.A. Abraham, S-Y. Yu, W.H. Choi, R.T.P. Lee, S.E. Mohney, Very low resistance alloyed Ni-based ohmic contacts to InP-capped and uncapped $\mathrm{n}^{+} \mathrm{In}_{0.53} \mathrm{Ga}_{0.47} \mathrm{As} \quad / / \quad$ J. Appl. Phys. 116(16) p. 1645061-1645066 (2014).

10. Wu Degi, Ding Wuchang, Yang Shansham, Jia Rui, Jin Zhi, Liu Xinyi, Optimization of ohmic contact for InP-based transferred electronic devices // $J$. Semiconductors, 35(3), p. 036001-036005 (2014).

11. P. Jian, D.G. Ivey, R. Bruce, G. Knight, Ohmic contact formation in palladium-based metallizations to n-type InP // J. Electron. Mater. 23(9), p. 953-962 (1994).

12. P. Maltsev, Yu. Fedorov, R. Galiev, S. Mikhailovich, D. Gnatyuk, Millimeter range nitride devices // Nanoindustry, 3(49), p. 40-51 (2014).

13. A. Dargys, J. Kundrotas, Handbook on Physical Properties of Ge, Si, GaAs and InP. Sci and Encyclopedia Publ., Vilnius, 1994.

14. S.J. Pearton, Processing of Wide Band Gap Semiconductors: Growth, Processing and Applications. Noyes Publ. Park Ridge. New Jersey, 2000.

15. A.V. Sachenko, A.E. Belyaev, N.S. Boltovets et al., Features of temperature dependence of contact resistivity in ohmic contacts on lapped $n-\mathrm{Si} / / \mathrm{J}$. Appl. Phys. 112(6), p. 063703-0637035 (2012).

16. V.P. Kladko, A.V. Kuchuk, P.M. Lytvyn et al., Substrate effects on the strain relaxation in GaN/AlN short-period superlattices // Nanosc. Res. Lett. 7(1), p. 289-299 (2012).

17. S.M. Sze, Kwok K. Ng, Physics of Semiconductor Devices. $3^{\text {rd }}$ ed. Wiley, New Jersey, 2007.

18. A.V. Sachenko, A.E. Belyaev, N.S. Boltovets et al., Mechanism of contact resistance formation in ohmic contacts with high dislocation density // $\mathrm{J}$. Appl. Phys. 111(8), p. 083701-083709 (2012). 